\title{
Avaliação das Propriedades Mecânicas de Material Polimérico Utilizado na Confecção de Caixas de Medição de Energia Elétrica
}

\author{
Ricardo J. Ferracin \\ Instituto de Tecnologia para o Desenvolvimento, Curitiba/PR \\ Adhemar Ruvolo Filho \\ Departamento de Química, UFSCar
}

José M. Marconcini

Embrapa Instrumentação Agropecuária, São Carlos/SP

José H. de 0 . Diniz

Departamento de Suprimentos, Companhia de Eletricidade do Estado da Bahia

\begin{abstract}
Resumo: As propriedades mecânicas de materiais poliméricos apresentam forte correlação com o processamento do material. Neste trabalho foram estudadas blendas de poli(óxido de fenileno)/poliestireno (PPO/PS) e policarbonatos utilizados na confecção de caixas, comparando-se as propriedades mecânicas de amostras injetadas nos formatos de corpo de prova, segundo a norma ASTM D638, e de amostras retiradas diretamente das caixas. A partir dos resultados de ensaio de impacto Izod verificou-se uma grande variabilidade nos valores antes e após envelhecimento em água, de todas as caixas. Isto se deve, principalmente, às diferentes tensões internas em cada região da caixa provenientes do processamento. Também foi observada uma grande diferença entre os valores encontrados para resistência ao impacto Izod dos corpos de prova retirados da parte inferior das caixas comparados com os valores encontrados para os respectivos materiais injetados, indicando também uma significativa influência dos parâmetros de processamento de injeção, tanto nas caixas como nos corpos de prova injetados. De modo geral, os valores de resistência à tração no ponto de máxima deformação elástica não diferem significativamente entre os corpos de prova injetados e os corpos de prova retirados das caixas do mesmo material; contudo, observou-se que esta variação é significativa nos valores de alongamento à ruptura, demonstrando que esta propriedade deve ser considerada nas avaliações do comportamento mecânico dos materiais poliméricos.
\end{abstract}

Palavras-chave: Policarbonato, blenda PPO/PS, propriedades mecânicas.

\section{Evaluation of Mechanical Properties of a Polymeric Material Used in the Construction of Boxes for Electrical Energy Measurements}

\begin{abstract}
The mechanical properties of polymeric materials depend strongly on the processing. In this work, blends of Poly(phenylene oxide)/polystyrene (PPO/PS) and polycarbonates used in electrical cabinet boxes have been studied. A comparison was made of the mechanical properties of samples injected in the form of test specimens, according to the standard practice ASTM D638, with test specimens removed from the boxes. From the results of impact Izod test, a great variability in the values was verified before and after ageing in water, for all the boxes. This is due to the different internal tensions in each region of the box arising from the processing. A large difference was observed among the values found for resistance to the impact Izod test of the removed test specimens of the lower part of the boxes compared with the values found for the respective injected materials. This indicates a significant influence from the parameters of injection processing, in the boxes as well as in the injected test specimens. Overall, the values of tensile strength in the point of maximum elastic deformation do not differ significantly among the test specimens injected and the removed from the boxes of the same material; however, it was observed that this variation is significant in the values of elongation at break, demonstrating that this property must be considered in the evaluations of the mechanical behavior of the polymeric materials.
\end{abstract}

Keywords: Polycarbonate, blend PPO/PS, mechanical properties. 


\section{Introdução}

Usualmente, a avaliação do desempenho de um produto baseado nas normas ASTM tem sido praticada a partir da confecção de corpos de prova $(\mathrm{CP})$, em geral através de injeção ou termoformagem diretamente das matérias-primas constituintes do produto.

No entanto, em materiais poliméricos, existe uma forte correlação entre a "história" de processamento e as propriedades do produto. Nesta correlação deve ser considerada a influência dos parâmetros de processamento tais como: temperatura de processamento, pressão, tempo, velocidade de resfriamento e geometria do molde, que em função das características reológicas e químicas do material polimérico serão determinantes na estrutura do produto obtido ${ }^{[1]}$.

O policarbonato (PC) é um termoplástico de engenharia com excelentes propriedades mecânicas, tais como: propriedades de impacto, estabilidade dimensional e alta temperatura de transição vítrea. No entanto, este material tem histórico de sensibilidade ao entalhe na propriedade de resistência ao impacto. A transição do comportamento de fratura dúctil para fratura frágil no policarbonato pode ser induzida, dentre vários fatores, aumentando-se a espessura da seção transversal, por aumento da velocidade do ensaio, pela diminuição da temperatura ou por introdução de falhas agudas, por exemplo, como resultado de envelhecimento ${ }^{[2]}$.

A sensibilidade ao entalhe pode ser descrita pela influência do raio de curvatura nas tensões ao redor de um buraco elíptico no material. Inberg e Gaymans ${ }^{[2]}$ testaram o policarbonato e blendas co-contínuas de policarbonato com ABS, com raios de entalhe obtidos por usinagem de $1 \mathrm{~mm}, 0,5 \mathrm{~mm}$, $0,25 \mathrm{~mm}$ e $0,1 \mathrm{~mm}$, e raios de $0,015 \mathrm{~mm}$ a $0,002 \mathrm{~mm}$, obtidos por laser. Para o policarbonato, o raio do entalhe mostrou um forte efeito na temperatura de transição frágil-dúctil. Esta temperatura aumentou com a diminuição do raio do entalhe, especialmente na faixa entre $0,1 \mathrm{~mm}$ e $0,5 \mathrm{~mm}$. Uma pequena variação no raio do entalhe ou uma falha na ponta do entalhe pode levar a um comportamento muito mais frágil. $\mathrm{O}$ entalhe padrão utilizado nos ensaios de impacto Charpy e Izod é de $0,25 \mathrm{~mm}$, que está situado no meio da faixa em que ocorre grande variação da resistência ao impacto com o raio do entalhe e, consequientemente, resultados dispersos são freqüentemente obtidos para estes ensaios. Um desvio a partir do raio do entalhe padrão de somente $0,01 \mathrm{~mm}$ já pode levar a uma alteração em $10{ }^{\circ} \mathrm{C}$ na temperatura de transição frágil - dúctil.

Chen e colaboradores estudaram o efeito das condições de processamento na moldagem por injeção de peças de paredes finas de policarbonato, tais como velocidade de injeção, temperatura de processamento, temperatura do molde e pressão de injeção nas propriedades de tração de policarbonatos. As espessuras de parede utilizadas em corpos de prova para o ensaio de tração utilizando-se de $\mathrm{CP}$ tipos gravata confeccionados de acordo com a norma ASTM D638, foram de $2,5 \mathrm{~mm}, 1,0 \mathrm{~mm}$ e $0,8 \mathrm{~mm}$. As tensões residuais foram medidas a partir de birrefringência com polaroscópio circular e métodos de fotoelasticidade ${ }^{[3]}$.

Os autores ${ }^{[3]}$ discutem que, a partir dos resultados obtidos, as tensões residuais têm um papel mais significante em influenciar as propriedades mecânicas do que as orientações moleculares induzidas pelo fluxo no processamento. A espessura e a velocidade de injeção foram os dois fatores primordiais que afetaram as tensões residuais mais significativamente dentro da janela de processamento utilizada. Quando a espessura diminui, há o aumento de tensões residuais, resultando na maior influência na redução da resistência à tração, tensão de escoamento, bem como o módulo de elasticidade.

Menores temperaturas de fusão, menores temperaturas de molde e corpos de prova de menor espessura resultam em grandes tensões residuais. Também foi observado que maiores pressões de empacotamento na injeção e tempos de preenchimento mais longos exibiram as maiores tensões residuais. A resistência à tração, a tensão de escoamento, assim como o módulo de elasticidade, aumentaram com o aumento da temperatura do fundido, da temperatura do molde e da velocidade de injeção ${ }^{[3]}$.

No resfriamento de polímeros amorfos a partir do estado líquido em equilíbrio, a transformação para o estado vítreo ocorre na temperatura de transição vítrea $\left(\mathrm{T}_{\mathrm{g}}\right)$, quando os rearranjos moleculares, os quais são necessários para o polímero acomodar-se à variação de temperatura, diminuem de tal modo que é necessária uma escala de tempo maior do que a imposta pela velocidade de resfriamento para que os rearranjos aconteçam. Se o resfriamento é levado a uma temperatura abaixo da $\mathrm{T}_{\mathrm{g}}$, o polímero apresentará quantidades termodinâmicas em excesso, como, por exemplo, volume, entalpia e entropia, e haverá uma força motriz para reduzilas aos seus valores de equilíbrio. Então, a uma temperatura constante abaixo da $\mathrm{T}_{\mathrm{g}}$, quando há tempo suficiente para que os movimentos moleculares previamente congelados sejam liberados, essas quantidades termodinâmicas irão diminuir, conduzindo ao fenômeno de envelhecimento físico. Devido a esta relação entre estrutura e propriedade dos polímeros, ao se envelhecer fisicamente um polímero, suas propriedades termodinâmicas irão variar com o tempo, conduzindo a mudanças em suas propriedades físicas, como por exemplo, as mecânicas e térmicas.

Ho e Vu-Khanh estudaram os efeitos do envelhecimento físico no policarbonato em suas propriedades térmicas ${ }^{[4]}$, de escoamento $^{[5]}$ e no comportamento do desempenho à fratura deste materia ${ }^{[5]}$. A partir da interpretação dos resultados de calorimetria exploratória diferencial (DSC), os autores observaram que o envelhecimento do policarbonato é um processo progressivo, envolvendo vários mecanismos. Os resultados concordam com o conceito de "enroscos" laterais das cadeias poliméricas, onde há um aumento na densidade de "enroscos" com o estágio de envelhecimento, o que leva a uma morfologia que requer temperaturas e energias maiores para ocorrerem os "desenroscos" moleculares. Sem envelhecimento físico, os policarbonatos estudados mantiveram-se 
duros e tenazes, enquanto que após envelhecimento tornaram-se mais frágeis. Em termos de movimentos moleculares, o processo de escoamento é um processo termicamente ativado, envolvendo movimentos inter e intramoleculares. Com relação às propriedades de fratura, o efeito do tempo de envelhecimento e da temperatura de envelhecimento foram investigados na faixa 0 a 96 horas e de 23 a $120{ }^{\circ} \mathrm{C}$, respectivamente. A tenacidade à fratura do policarbonato diminuiu continuamente nas faixas de tempo e temperatura estudadas, mostrando que o envelhecimento físico leva a mudanças na resistência à fratura deste material.

As blendas de poli(óxido de fenileno) (PPO) e poliestireno (PS) foram desenvolvidas na década de 60 do século XX, atualmente apresentando uma família de mais de 30 tipos de resina. Essencialmente, esta blenda é composta de poli(óxido de fenileno) (PPO), de $\mathrm{T}_{\mathrm{g}}$ alta, em torno de $210-220^{\circ} \mathrm{C}$, sendo um polímero de custo mais elevado, de difícil processabilidade e boas propriedades mecânicas, e do poliestireno amorfo (PS), com $\mathrm{T}_{\mathrm{g}}$ menor, em torno de $100{ }^{\circ} \mathrm{C}$, que é responsável pela melhoria na processabilidade da blenda e redução de custos. Estes polímeros formam uma blenda miscível, porém com morfologia e propriedades dependentes da composição e da condição de processamento da blenda ${ }^{[7]}$.

Ho e colaboradore ${ }^{[8]}$ estudaram o comportamento de deformação plástica da blenda PPO/PS em toda a faixa de composições da blenda, observando a correlação entre volume de ativação de cisalhamento e densidade de "enroscos" moleculares. Um parâmetro chave para se entender os mecanismos de deformação plástica de sólidos vítreos em nível molecular é o tamanho das regiões em que ocorrerão transformações por cisalhamento. Os resultados sugerem que há uma cooperação entre os processos elementares nas escalas de deformação plástica das blendas e a densidade de "enroscos" moleculares. Como a densidade de "enroscos" moleculares varia em função da composição da blenda, as propriedades que dependem da deformação plástica, tais como resistência à fratura e alongamento na ruptura, podem apresentar mudanças com a variação da composição das blendas e com o processamento.

Em estudos de Suzuki e colaboradores ${ }^{[9]}$, por meio da análise de propriedades de transporte de gás ${ }^{129} \mathrm{Xe}$ - sorção e permeação - utilizando ressonância magnética nuclear (RMN), os autores demonstraram que o volume médio dos microvazios individuais varia não linearmente de $7,1 \mathrm{~nm}$, para o PS, a 12,6 nm, para o PPO. O aumento da fração volumétrica de PPO na blenda indica que há uma contração nos microvazios durante o processo de blendagem. Esta contração dos microvazios nas blendas afeta fortemente as propriedades de transporte de gases na blenda e demonstra também que há uma forte correlação entre a composição de blendas, sua microestrutura e propriedades.

Devido aos fatores expostos anteriormente, onde se observa uma forte influência de composição, parâmetros de processamento e ensaios nas propriedades dos materiais poliméricos estudados, o objetivo deste trabalho é a compara- ção de resultados de propriedades mecânicas entre corpos de prova injetados e retirados diretamente de caixas injetadas, avaliando-se o efeito das diferentes condições de processamento e preparação de corpos de prova nas propriedades mecânicas de policarbonatos e de blendas PPO/PS.

\section{Experimental}

\section{Materiais utilizados}

As caixas confeccionadas em materiais poliméricos eram compostas de duas partes distintas: a base e a tampa. Na confecção da base das caixas, os materiais poliméricos que foram injetados em moldes propositalmente com formato irregular, foram os seguintes: duas Blendas de PPO/PS com diferentes composições, identificadas neste trabalho como PPO/PS A e PPO/PS B e dois tipos diferentes de Policarbonato, identificados como PC A e PC B.

$\mathrm{Na}$ injeção das tampas das caixas foram utilizados dois tipos de policarbonato, distintos daqueles utilizados na confecção das bases das caixas. Os materiais poliméricos utilizados na injeção das tampas de caixas manufaturadas foram os seguintes: Policarbonato C, identificados como PC C1, PC $\mathrm{C} 2$ e PC C3, provenientes de 3 tampas diferentes injetadas com o mesmo policarbonato $\mathrm{C}$, e Policarbonato D, identificado como PC D.

A escolha deste tipo de codificação para as amostras se deve ao fato, das mesmas serem materiais comerciais de uso corrente no Brasil. As diferenças principais se referem aos valores de índice de fluidez e no caso das blendas de PPO/PS nos teores de PPO e PS.

\section{Injeção das bases e das tampas das caixas}

As bases e tampas das caixas foram injetadas segundo o modelo apresentado na Figura 1.

Para a injeção foi utilizada uma máquina injetora Battenfeld FC 3000/1600, nas seguintes condições:

a) Blenda PPO/PS:

- Secagem da blenda a $80^{\circ} \mathrm{C}$ por 8 horas

- Perfil de temperaturas: $215 / 225 / 240 / 250 / 250$

- Temperatura do molde: $55^{\circ} \mathrm{C}$

b) Policarbonato:

- Secagem do material a $120^{\circ} \mathrm{C}$ por 48 horas

- Perfil de temperaturas: $260^{\circ} \mathrm{C} / 270^{\circ} \mathrm{C} / 280^{\circ} \mathrm{C} / 275^{\circ} \mathrm{C}$ $1280{ }^{\circ} \mathrm{C}$

Temperatura do molde: $70^{\circ} \mathrm{C}$

\section{Preparação dos corpos de prova (CP)}

a) Corpos de prova retirados diretamente das bases e das tampas das caixas injetadas.

Os corpos de prova foram confeccionados diretamente a partir das bases e das tampas das caixas injetadas,a partir de diferentes partes (lateral, frontal ou fundo), na forma de gravatas atendendo a geometria de corpos de prova tipo IV, norma ASTM D638, por meio de fresamento mecânico. 

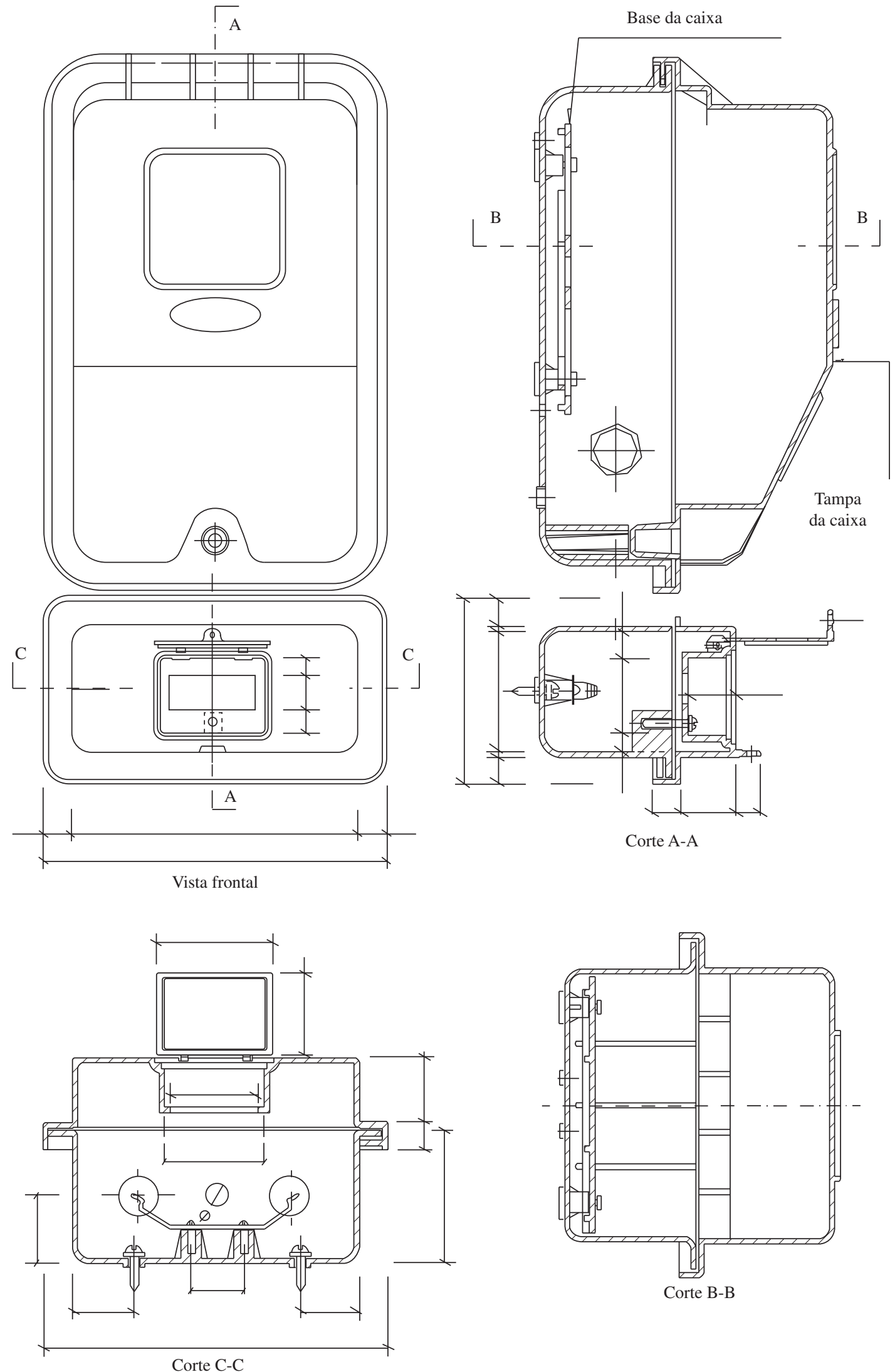

Figura 1. Modelo da base e tampa das caixas injetadas. 
Os corpos de prova retirados diretamente do produto foram ensaiados de forma aleatória a partir de diferentes partes (laterais, frontal ou fundo) constituintes da base ou da tampa das caixas.

b) Corpos de prova injetados

Os corpos de prova foram confeccionados por moldagem por injeção a partir das matérias-primas virgens, na geometria de gravatas tipo IV segundo norma ASTM D638, nas mesmas condições de injeção utilizadas para as caixas e descritas anteriormente.

\section{Envelhecimento em água}

O envelhecimento em água foi realizado segundo a norma UL 746C, onde os corpos de prova foram imersos em água destilada a $70,0 \pm 1,0^{\circ} \mathrm{C}$, por um período de 7 dias, com uma troca completa de água realizada após o período de 5 dias. Após o condicionamento em água por 7 dias, os corpos de prova foram imersos em água destilada a $23,0 \pm 2,0{ }^{\circ} \mathrm{C}$ por meia hora imediatamente antes dos ensaios.

\section{Envelhecimento sob radiação ultravioleta}

O envelhecimento sob radiação ultravioleta foi realizado em câmara de envelhecimento acelerado com lâmpada de xenônio por um período de 1000 horas, segundo a norma UL 746C.

\section{Envelhecimento em cimento}

$\mathrm{O}$ envelhecimento em cimento foi realizado segundo o seguinte procedimento: Preparou-se uma solução 1:1 em massa de cimento portland e água, em um recipiente inerte. Agitou-se vigorosamente a solução, obtendo-se uma mistura. Deixou-se a solução descansar por alguns minutos e agitando-a novamente. Após se misturar pela segunda vez e deixar a solução descansar novamente, os corpos de prova foram totalmente imersos na solução pelo período de uma hora, à temperatura ambiente. $\mathrm{O}$ pH medido desta solução foi de 12,9 , caracterizando esta solução como fortemente alcalina. Na seqüência, os corpos de prova foram então retirados da solução, lavados com água destilada e secos.

\section{Ensaios de impacto Izod}

Os ensaios de impacto Izod foram realizados nos corpos de prova injetados e nos retirados diretamente das bases e tampas das caixas, sem e com envelhecimento em água ou cimento. Os corpos de prova foram entalhados com um dispositivo de entalhe JT Tohsi tipo TVH-603. A máquina de ensaio impacto utilizada foi uma X-JU 22 e os ensaios realizados segundo as normas ASTM D256 e UL 746C.

\section{Ensaios mecânicos de flexão}

Os ensaios mecânicos de flexão foram realizados nos corpos de prova injetados e nos retirados diretamente das bases e tampas das caixas, sem e com envelhecimento em água ou sob radiação ultravioleta, em uma máquina universal de en- saios mecânicos INSTRON, modelo 4467, segundo a norma ASTM D790.

\section{Ensaios mecânicos de tração}

Os ensaios mecânicos de tração foram realizados nos corpos de prova injetados e nos retirados diretamente das bases e tampas das caixas, sem e com envelhecimento em água ou sob radiação ultravioleta, em uma máquina universal de ensaios mecânicos INSTRON, modelo 4467, segundo a norma UL746C.

\section{Avaliação dos resultados}

Os resultados de cada propriedade foram avaliados pela média (representada pelas colunas dos gráficos) e desvio padrão (representado pelas barras dos gráficos) de pelo menos 5 corpos de prova ensaiados.

\section{Resultados e Discussão}

Com base no conjunto de resultados envolvendo ensaios mecânicos de impacto, flexão e tração, em corpos de prova (CP) sem envelhecimento e após envelhecimento em imersão em água (norma UL 746C) e sob radiação ultravioleta (UV) (UL746C) nas Figuras de 2 a 10 estão apresentados, de forma conjunta, os resultados obtidos da propriedade mecânica em função do conjunto de materiais analisados para base ou para tampa de forma agregada em grupos de amostras. Deste modo, foi possível comparar a metodologia de preparação de corpos de prova injetados a partir da matéria prima ou retirados diretamente do produto, de forma aleatória, em diferentes partes (laterais, frontal ou fundo) constituintes da base ou da tampa das caixas.

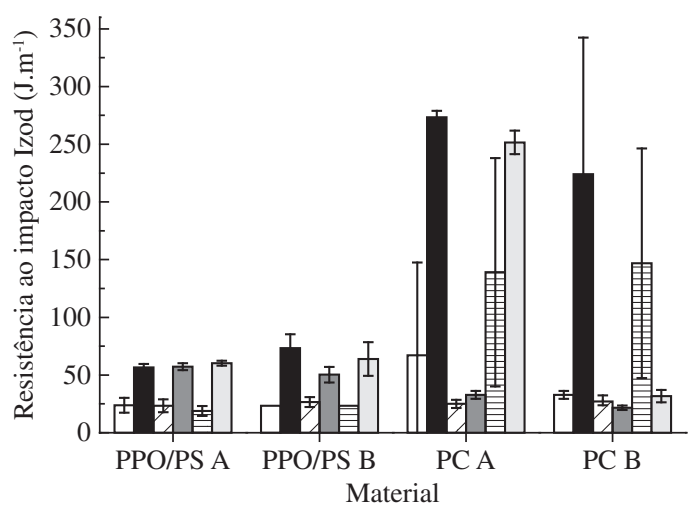

$$
\begin{aligned}
& \text { Base da caixa } \\
& \text { CP retirado do produto; sem envelhecimento. } \\
& \text { CP injetado; sem envelhecimento. } \\
& \text { CP retirado do produto; envelhecido em água. } \\
& \text { CP injetado; envelhecido em água. } \\
& \square \text { CP retirado do produto; envelhecido em cimento. } \\
& \square \text { CP injetado; envelhecido em cimento. }
\end{aligned}
$$

Figura 2. Resultados do ensaio de impacto Izod a partir de corpos de prova (CP) retirados do produto e injetados para os materiais utilizados na confecção das bases das caixas. 


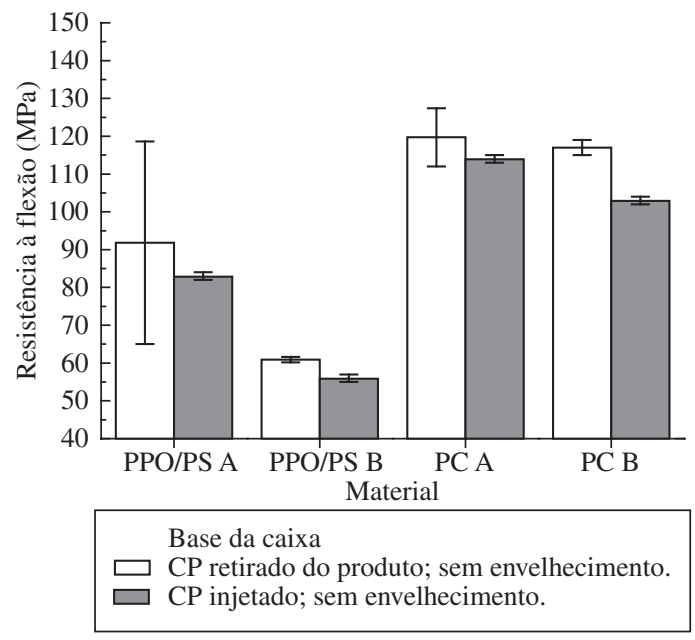

Figura 3. Resultados de resistência à flexão a partir de corpos de prova (CP) retirados do produto e injetados para os materiais utilizados na confecção das bases das caixas.

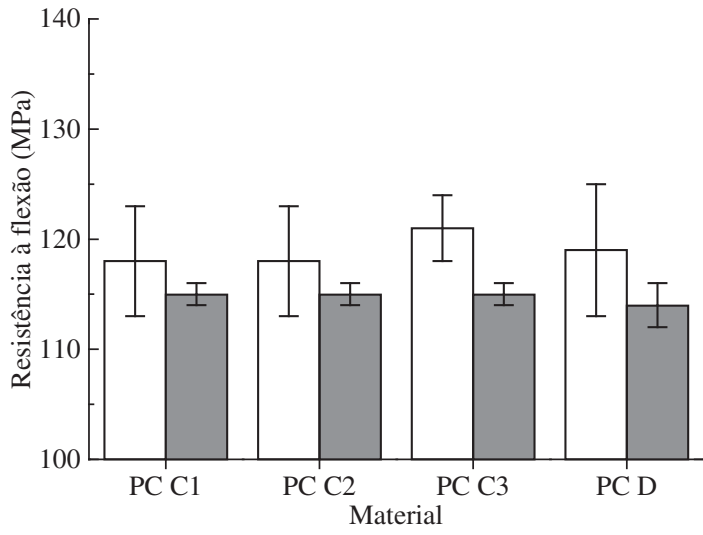

Tampa da caixa $\square$ CP retirado do produto; sem envelhecimento. $\square \mathrm{CP}$ injetado; sem envelhecimento.

Figura 4. Resultados de resistência à flexão a partir de corpos de prova $(\mathrm{CP})$ retirados do produto e injetados para os materiais utilizados na confecção das tampas das caixas.

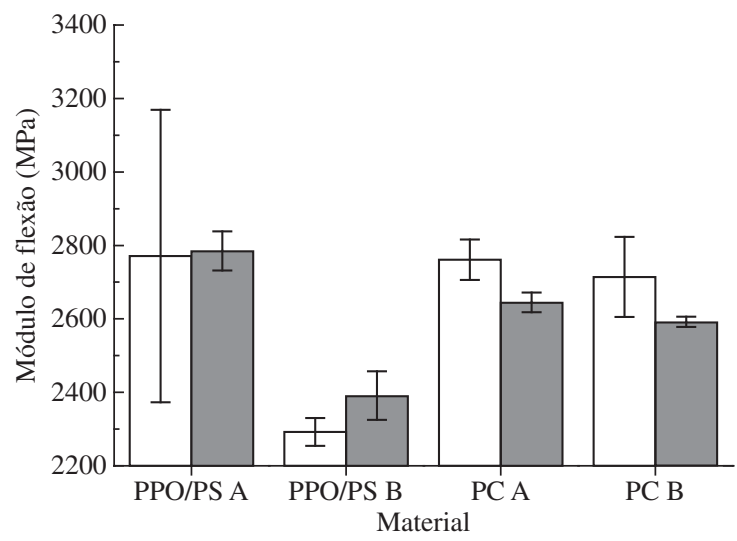

Base da caixa

$\square$ CP retirado do produto; sem envelhecimento $\square$ CP injetado; sem envelhecimento.

Figura 5. Resultados do módulo de flexão a partir de corpos de prova $(\mathrm{CP})$ retirados do produto e injetados para os materiais utilizados na confecção das bases das caixas.

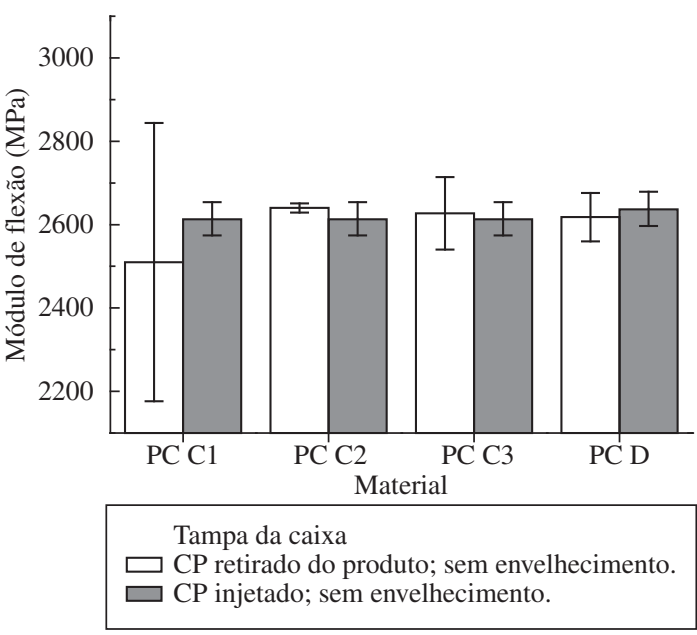

Figura 6. Resultados do módulo de flexão a partir de corpos de prova (CP) retirados do produto e injetados para os materiais utilizados na confecção das tampas das caixas.

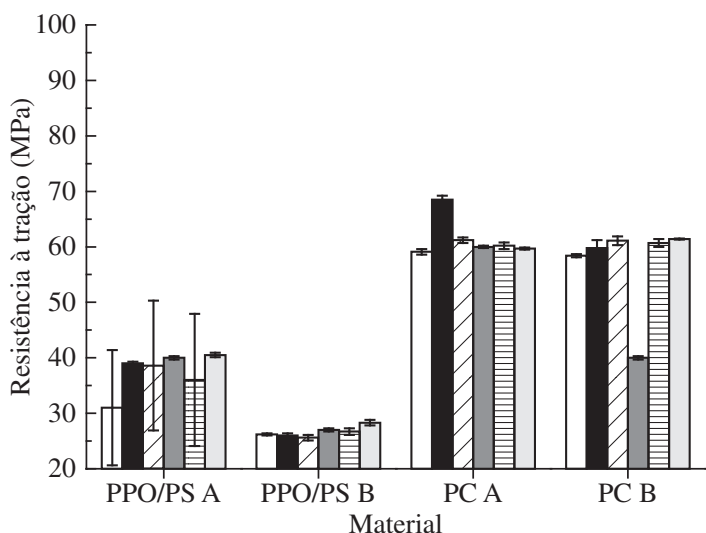

Base da caixa

$\square$ CP retirado do produto; sem envelhecimento.

- CP injetado; sem envelhecimento.

ZCP retirado do produto; envelhecido em água.

$\square$ CP injetado; envelhecido em água.

$\Longrightarrow \mathrm{CP}$ retirado do produto; envelhecido sob UV. $\square$ CP injetado; envelhecido sob UV.

Figura 7. Resultados de resistência à tração a partir de corpos de prova (CP) retirados do produto e injetados para os materiais utilizados na confecção das bases das caixas.

Os resultados apresentados nestas figuras correspondem aos valores médios de pelo menos 5 réplicas e com seus respectivos desvios padrões.

De forma geral, considerando-se todas as propriedades analisadas, observa-se que os valores médios para os corpos de prova injetados são acentuadamente diferentes daqueles correspondentes dos corpos de provas retirados diretamente do produto. No entanto, com relação aos desvios padrões, aqueles correspondentes aos corpos de prova extraídos diretamente do produto são acentuadamente maiores que os desvios padrão dos corpos de prova injetados.

Estas diferenças nos valores das propriedades e nos seus respectivos desvios padrão apontam para o fato de que um valor da propriedade estimada diretamente em um corpo de 


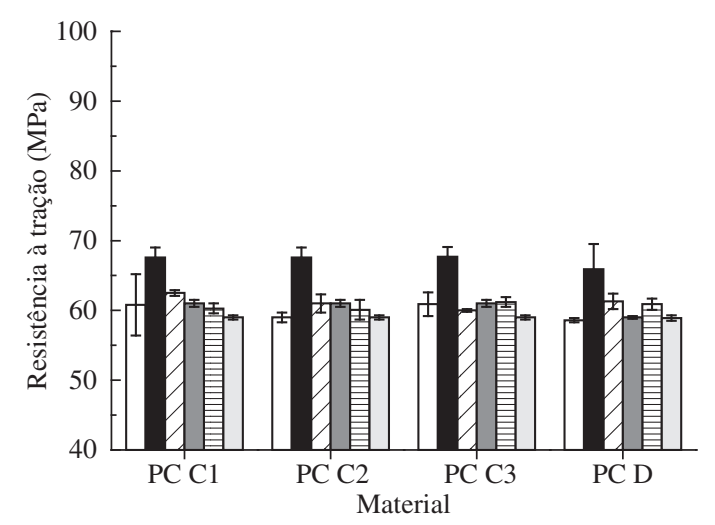

Tampa da caixa
CP retirado do produto; sem envelhecimento.
CP injetado; sem envelhecimento.
$\square$ CP retirado do produto; envelhecido em água.
CP injetado; envelhecido em água.
CP retirado do produto; envelhecido sob UV.
CP injetado; envelhecido sob UV.

Figura 8. Resultados de resistência à tração a partir de corpos de prova (CP) retirados do produto e injetados para os materiais utilizados na confecção das tampas das caixas.

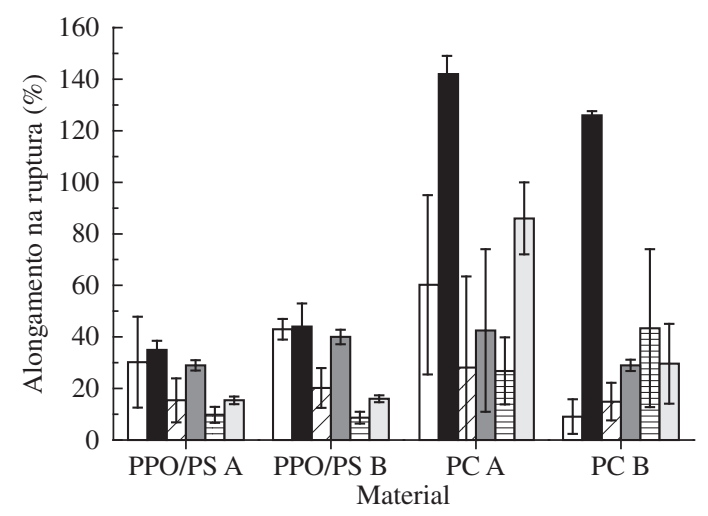

Base da caixa

$\square$ CP retirado do produto; sem envelhecimento.

CP injetado; sem envelhecimento.

$\square$ CP retirado do produto; envelhecido em água. $\square$ CP injetado envelhecido em água.

$\Xi$ CP retirado do produto; envelhecido sob UV. $\square$ CP injetado; envelhecido sob UV.

Figura 9. Resultados de alongamento na ruptura a partir de corpos de prova (CP) retirados do produto e injetados para os materiais utilizados na confecção das bases das caixas.

prova injetado estatisticamente não representa o valor real da propriedade quando estimada diretamente em um corpo de prova retirado do produto. Seria importante, a partir destas considerações iniciais, com base apenas nos valores numéricos encontrados, que se apresentassem um conjunto de considerações, tendo em vista as possíveis correlações e efeitos de natureza físico-química envolvendo os parâmetros de processamento, a geometria do molde, as características reológicas e químicas dos materiais estudados, as quais serão determinantes na consolidação da sua estrutura e da sua resposta nas propriedades mecânicas de impacto, flexão e tração.

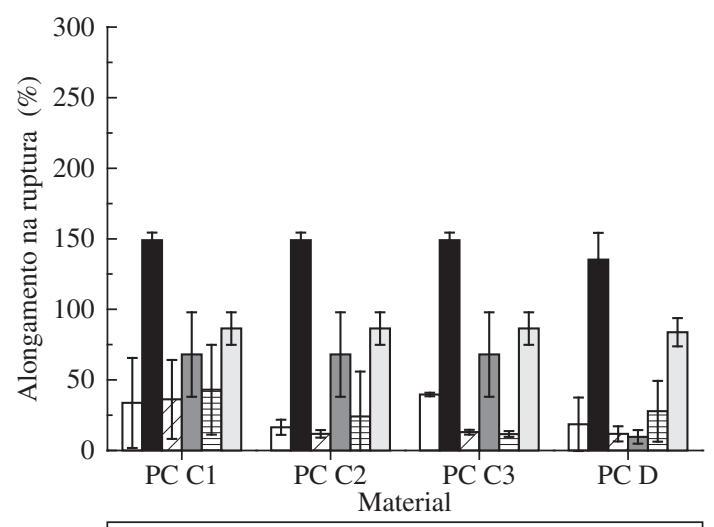

Tampa da caixa

$\square$ CP retirado do produto; sem envelhecimento - CP injetado; sem envelhecimento.

$\square$ CP retirado do produto; envelhecido em água. $\square$ CP injetado envelhecido; em água. $\Xi \mathrm{CP}$ retirado do produto; envelhecido sob UV $\square$ CP injetado; envelhecido sob UV.

Figura 10. Resultados de alongamento na ruptura a partir de corpos de prova (CP) retirados do produto e injetados para os materiais utilizados na confecção das tampas das caixas.

\section{Ensaio de Impacto Izod}

Como pode ser observado na Figura 2, com relação aos materiais utilizados na base da caixa, a propriedade de resistência ao impacto Izod tem uma acentuada redução após envelhecimento em água para os corpos de prova (CP) injetados.

No entanto, no caso da resina PPO/PS B, observa-se uma pequena diminuição para o corpo de prova injetado enquanto que no corpo de prova extraído do produto a propriedade mantém-se praticamente constante, considerando-se o desvio padrão. Para a blenda PPO/PS A praticamente não se observa variação após o envelhecimento em água, independente do tipo de corpo de prova. Estes resultados sugerem que a diminuição observada nos policarbonatos pode ser explicada por um efeito plastificante da água durante o período de envelhecimento de imersão dos corpos de prova que, segundo a norma UL $746 \mathrm{C}$, é realizado por 7 dias a $70{ }^{\circ} \mathrm{C}$. Por outro lado, considerando-se os desvios padrão, é possível afirmarse que o envelhecimento em água não tem influência na blenda PPO/PS.

Com relação ao envelhecimento por contato com cimento, não foi observado nenhum efeito na blenda PPO/PS, independente do tipo de corpo de prova. No entanto, para as resinas policarbonato PC B, considerando os desvios padrão e seus valores mínimos e máximos, principalmente para os corpos de prova retirados diretamente do produto, é possível afirmar-se que não há efeito do contato com o cimento na resistência ao impacto desse material. Por outro lado, para o policarbonato PC A, no caso dos corpos de prova retirados diretamente do produto, mesmo tendo em conta a grande variabilidade dos limites máximo e mínimo dos desvios padrão observados nos corpos de prova envelhecidos, é possível 
afirmar-se que o envelhecimento causou aumento na resistência ao impacto nos corpos de prova extraídos diretamente do produto. Contrariamente, os resultados obtidos com corpos de prova injetados mostram uma diminuição na resistência ao impacto para o material envelhecido.

Estes resultados opostos obtidos sobre um mesmo tipo de material só podem ter sua origem no efeito do processamento sobre a propriedade analisada. Considerando-se as geometrias dos moldes utilizados para a obtenção do produto caixa e do corpo de prova tipo gravata, seguramente as diferenças na concepção geométrica nos dois moldes, tendo em conta sua influência nos fluxos do material fundido através dos canais de injeção que tem comprimento e diâmetro distintos, é plausível admitir-se que no produto exista um nível maior de concentração de tensões não homogêneas congeladas. Estas diferenças de processamento conduziram a maiores e mais acentuadas variações encontradas nos valores médios das propriedades e nos valores máximos e mínimos dos desvios padrão estimados para todas as propriedades estudadas, no caso dos corpos de prova retirados diretamente das caixas.

Por outro lado, é conhecido o fato de que os poliésteres (caso típico dos policarbonatos) podem sofrer reações de hidrólise em meio alcalino. Do ponto de vista cinético, a velocidade dessa reação é função da concentração do meio alcalino e da temperatura ${ }^{[10,11]}$. O ensaio de envelhecimento em cimento foi realizado conforme descrito na parte experimental mantendo-se a amostra mergulhada em uma mistura de cimento em água 1:1 $(\mathrm{pH}=12,9)$ à temperatura ambiente por 1 hora. Neste caso, a mistura cimento água, tendo em vista a composição química do cimento, pode ser considerada uma solução fortemente alcalina.

De acordo com a literatura, as reações de hidrólise de poliéster em meio aquoso, quando realizadas em temperaturas próxima da fervura da água, mas muito abaixo da temperatura de fusão do poliéster, ocorrem numa velocidade muito lenta, sendo que os produtos de degradação surgem após períodos que podem superar mais de 15 dias $^{[9,10]}$.

No artigo de Silva et al. ${ }^{[12]}$, os autores testaram o poli(tereftalato de etileno) (PET) em três soluções alcalinas: solução saturada de $\mathrm{Ca}(\mathrm{OH})_{2}(\mathrm{pH}=12,3)$, solução $0,1 \mathrm{M}$ de $\mathrm{NaOH}(\mathrm{pH}=13)$ e solução de Lawrence $\left(0,48 \mathrm{~g} \cdot \mathrm{L}^{-1}\right.$ $\mathrm{Ca}(\mathrm{OH})_{2}+3,45$ g. $\mathrm{L}^{-1} \mathrm{KOH}+0,88$ g.L $\left.\mathrm{L}^{-1} \mathrm{NaOH}, \mathrm{pH}=12,9\right)$. A solução de Lawrence é uma solução aquosa que simula o ambiente de uma pasta de cimento completamente hidratada. Os autores concluíram que as fibras de PET reciclado interagem com $\mathrm{Ca}(\mathrm{OH})_{2}$ e com soluções de Lawrence, tornando a superfície do polímero mais rugosa e precipitando fases identificadas como tereftalatos alcalinos, após um período de 164 dias a 5,25 e $50{ }^{\circ} \mathrm{C}$. A tenacidade dos compósitos de cimento Portland/PET nos ensaios de flexão aumentou quando as fibras de PET estavam presentes. Porém, devido à degradação das fibras dentro dos compósitos, a tenacidade dos compósitos diminuiu com o tempo. Após um período de 164 dias, a partir de imagens de microscopia eletrônica de varredura, foi observada a degradação das fibras nos compó- sitos, apresentando superfície totalmente rugosa e se observando também que a degradação completa das fibras pode ocorrer. $\mathrm{O}$ ataque nas fibras do polímero é superficial e ocorre nos grupos carboxílicos gerando assim microfissuras no polímero (ou micro enervamentos localizados).

Estes resultados corroboram os resultados observados de diminuição da resistência ao impacto nas amostras retiradas diretamente do produto, onde o elemento catalisador da degradação pode ser devido às tensões não homogêneas do processamento. Isto, no caso das amostras injetadas, pode levar a degradação superficial, propiciando a ruptura de ligações devido ao ataque em grupos carboxílicos, seguido de formação de microfissuramento, fragilizando o material.

No entanto, a reatividade é acentuadamente aumentada, diminuindo o tempo de reação na ordem de 24 a 48 horas se a hidrólise for conduzida em temperaturas próximas ou superiores à fusão do poliéster, e obviamente neste caso, sob elevados valores de pressão ${ }^{[13]}$. Toda esta análise mostra que uma possível reação de hidrólise na matriz de policarbonato, cuja temperatura de transição vítrea é da ordem de $150{ }^{\circ} \mathrm{C}$, enquanto que a temperatura de deflexão ao calor sob carga está na faixa de $130^{\circ} \mathrm{C}$; se ocorrer deverá ser muito lenta à temperatura ambiente, porém possivelmente dependente da alcalinidade do meio e do histórico de processamento do material em termos de nível de concentração de tensões internas congeladas. A influência da temperatura e da alcalinidade do meio reacional, na reação de hidrólise de poliésteres pode ser confirmada em um artigo publicado pelo nosso grupo, sobre a despolimerização do PET em meio alcalino ${ }^{[14]}$.

A reação química de hidrólise entre um poliéster no estado sólido imerso em um meio alcalino deve ser vista como um processo heterogêneo, com várias etapas envolvendo transporte de massa e reação química. No caso de considerarse a reação química ocorrendo superficialmente no sólido polimérico, o mecanismo poderia ser subdividido nas seguintes etapas:

i) Difusão das espécies alcalinas solubilizadas na água até a superfície do sólido;

ii) Adsorção das espécies em sítios ativos (preferencialmente em grupos polares na superfície do sólido);

iii) Reação química com a formação de produtos na superfície do sólido; e

iv) Difusão dos produtos formados para a solução.

Neste caso, com o transcorrer do tempo de reação, se não houver uma efetiva retirada dos produtos de reação formados na superfície do material polimérico, o processo cinético poderá ter a sua velocidade tanto mais diminuída quanto menor for a velocidade de difusão dos produtos formados na superfície do sólido para o meio líquido aquoso. Neste caso, o processo passaria a ser controlado pelo transporte de massa do produto formado. Se considerar-se que na superfície do sólido, além dos sítios polares reativos também possam existir defeitos na forma de fissuras e microfissuras, que tem sua origem na concentração de tensões originadas no processamento do material polimérico, então deveria ser acrescida 
uma nova etapa mecanística àquelas apresentadas anteriormente.

Esta etapa refere-se à adsorção e agregação das espécies alcalinas solubilizadas nas bordas e no interior dos defeitos. Este fenômeno pode aumentar de forma significativa o tempo para difusão de produtos formados na superfície e no interior dos defeitos para o seio da solução. Como consequiência, a reação de hidrólise seria controlada prevalentemente pelo transporte de massa.

Em condições experimentais tais que a solução alcalina não é em momento algum agitada e sendo a reação de hidrólise controlada pelo transporte de massa, sua velocidade poderá ser sensivelmente diminuída.

Toda essa análise, se correta, quando aplicada ao experimento de envelhecimento em cimento, permitiria a proposição da seguinte hipótese como explicação para os resultados de impacto encontrados no sistema PC A: admitindo-se que o nível de tensões congeladas nos corpos de prova injetados deve ser acentuadamente menor do que aqueles presentes nos corpos de prova retirados diretamente dos produtos, principalmente tendo-se em conta as diferenças de concepções geométricas entre os moldes, é possível que uma reação de hidrólise nos corpos de prova extraídos diretamente dos produtos seria preferencialmente controlada pelo transporte de massa e, portanto, muito provavelmente com tempo de reação superior àquele que ocorre no ensaio de envelhecimento realizado neste trabalho.

Como conseqüência do maior tempo de retenção da solução aquosa no interior dos defeitos (microfissuras, por exemplo) gerados pelo acúmulo de tensões, poderia se ter um efeito de relaxação (plasticização) da matriz polimérica, mais do que um efeito de degradação via reação química de hidrólise. Sendo esta hipótese verdadeira, esperar-se-ia que o envelhecimento por contato com cimento poderia levar a um relaxamento dos corpos de prova retirados do produto e a certo nível de degradação via reação química dos corpos de prova injetados. Isto explicaria o leve aumento na resistência ao impacto Izod observado nos corpos de prova retirados do produto e a acentuada diminuição nesta propriedade observada nos corpos de prova injetados.

Acredita-se que se o ensaio fosse prolongado por tempo mais longo, provavelmente o pequeno aumento observado na resistência ao impacto dos corpos de prova retirados diretamente do produto seria seguido de uma diminuição contínua na resistência ao impacto, como conseqüência da possível complementação da reação de hidrólise no interior dos defeitos existentes nestes corpos de prova.

\section{Ensaio de Flexão}

Nas Figuras de 3 a 6 estão apresentados os resultados dos ensaios de flexão realizados para os materiais das bases e tampas das caixas.

Durante o ensaio de flexão, à medida que o corpo de prova se deforma assumindo um perfil curvo, a distribuição de tensões através de uma linha média no eixo longitudinal corresponderá a dois tipos de esforços resultantes: tração e compressão. Nesse estado de tensões, as propriedades resultantes serão fortemente dependentes da morfologia do material e principalmente da sua natureza homogênea (1 fase) ou heterogênea ( 2 ou mais fases). No caso específico dos materiais estudados, policarbonato ou PPO/PS, que é uma blenda de poliestireno (PS) e poli(óxido de fenileno) (PPO), diferentes morfologias que resultam em fases amorfas ou cristalinas e portanto em um material semicristalino, devem ser descartadas uma vez que esses sistemas aqui estudados se apresentam totalmente amorfos. Entretanto, embora a blenda PPO/PS é de natureza amorfa, ela é composta por uma mistura de dois materiais quimicamente distintos, e neste caso os conceitos de miscibilidade e compatibilidade são fundamentais uma vez que são decisivos no tipo de interfaces geradas durante o processamento. Com base nestas afirmações e considerando-se sempre a acentuada variação nos limites máximos e mínimos para os valores do desvio padrão encontrados nas propriedades dos corpos de prova retirados diretamente dos produtos, pode-se considerar (excetuando-se o conjunto de $\mathrm{CP}$ das amostras PCB e PC C3) que tanto a resistência como o módulo de flexão do conjunto de corpos de prova a base de policarbonato praticamente não mostram diferenças nestas propriedades, estatisticamente significativas, quando os corpos de prova são retirados diretamente do produto ou injetados.

Por outro lado, quando se considera o conjunto de corpos de prova produzidos com a blenda PPO/PS o que se observa, independentemente do tipo de corpo de prova, é que a resistência e o módulo de flexão da blenda PPO/PS A é maior do que os valores observados para a blenda PPO/PS B.

Como neste caso trata-se de um material composto por dois polímeros distintos, PPO e PS, a diminuição observada na blenda PPO/PS B muito provavelmente está relacionada a uma maior concentração de poliestireno neste material, tendo em vista que os valores destas propriedades para o poliestireno puro são inferiores àquelas que para o PPO puro ${ }^{[15]}$

Uma observação importante que deve ser assinalada é que o conjunto de resultados de resistência à flexão para todos os policarbonatos utilizados é sempre superior aos obtidos para as blendas PPO/PS. Este fato expressa a importância do conceito de molhabilidade e resistência da interface entre os constituintes de naturezas químicas distintas no caso da blenda PPO/PS. Esta diferença não fica evidente no módulo de flexão.

Enquanto a resistência à flexão medida no ponto de máxima deformação elástica traduz a resistência limite do material aos esforços de flexão antes do material romper ou escoar plasticamente, a propriedade módulo de flexão simplesmente representa a taxa de variação da tensão em função da deformação do material dentro do regime elástico. Portanto, se considerarem-se comparativamente materiais de natureza química distinta, porém com uma estrutura química que confere às cadeias acentuada ou elevada rigidez; na região 
elástica ou de pequenas deformações (inferiores a $2 \%$ onde normalmente o módulo é calculado espera-se muito pouca influência deve ocorrer na razão entre as tensões resultantes e a deformação.

\section{Ensaio de Tração}

Da Figura 7 a 10 estão apresentados os resultados do ensaio de tração

De maneira análoga aos ensaios de flexão, nos resultados dos ensaios de tração, a resistência medida no ponto de ruptura evidencia dois aspectos importantes:

i) os resultados obtidos para o conjunto de amostras de policarbonato são superiores estatisticamente àqueles obtidos pelo conjunto à base da blenda PPO/PS; e

ii) os resultados obtidos com o conjunto de corpos de prova à base de policarbonato extraídos da tampa mostram claramente as diferenças entre a propriedade medida nos corpos de prova injetados e retirados do produto, sendo neste caso sempre superiores quando medidas sobre o corpo de prova injetado.

Estas duas observações tornam claro e corroboram dois fenômenos já discutidos: o efeito das tensões não homogêneas congeladas provenientes do processamento do material, e um possível efeito de interfaces no PPO/PS, caso a mistura do mesmo não tenha sido realizada de forma efetiva para obterse uma blenda totalmente miscível. Um futuro estudo morfológico da blenda poderia esclarecer esta última hipótese.

Com relação aos resultados de alongamento na ruptura, inicialmente é importante assinalar que esta propriedade limite é proporcional à energia necessária para deformar elasticamente o material, alterando a sua microestrutura morfológica, passando para um regime de escoamento plástico até o limite de ruptura. Em todo esse processo, estão envolvidos alinhamento de cadeias em regiões amorfas e destruição de estruturas micro e macrocristalinas (no caso de materiais semicristalinos), com conseqüente formação de estruturas fibrilares. Durante a exposição de um material polimérico a um processo de envelhecimento, a estrutura original pode sofrer transformações em função do tipo e da intensidade do envelhecimento. Particularmente, como exemplo a água, dependendo do grau de hidrofobicidade da matriz polimérica, tanto pode atuar como um agente plastificante como um agente antiplastificante.

No primeiro caso, dependendo do grau de plasticização, a matriz polimérica pode adquirir mobilidade suficiente a ponto de ocorrer fenômenos de cristalização induzida devido à interação com a água preferencialmente localizada em espaços inter macromoleculares. Já no segundo caso, e em função da polaridade relativa da matriz polimérica, a interação da água com grupos polares da matriz pode atingir níveis tais que sua difusão na fase volume da matriz polimérica permita sua localização em espaços localizados nas regiões intra e supra macromoleculares e como consequiência, pode-se observar um fenômeno de antiplasticizaçãa ${ }^{[13,16]}$.
No primeiro caso, normalmente o material se torna mais flexível, enquanto que no segundo caso, é observado um enrijecimento da matriz polimérica.

Com relação ao envelhecimento, como por exemplo, sob radiação ultravioleta, de forma geral os fenômenos de degradação observados são atribuídos às reações de fotodegradação. Neste caso podem ocorrer cisões de cadeias, recombinação com entrecruzamento, redução de massa molar, reações de transesterificação, formação de subprodutos voláteis ou oligômeros entre outros ${ }^{[17]}$.

Especificamente no caso dos materiais aqui estudados, poliésteres (policarbonato) e a blenda PPO/PS, esperar-se-ia, no primeiro caso, possíveis reações de transesterificação e no segundo caso, reações envolvendo cisão de cadeia com redução na massa molar ${ }^{[18]}$.

Com relação aos resultados obtidos, os seguintes aspectos importantes devem ser destacados:

i) No conjunto dos corpos de prova de policarbonato fica extremamente evidente o efeito do processamento nas suas propriedades relacionadas ao seu desempenho mecânico. Observam-se diferenças que podem chegar a até 6 vezes entre os corpos de prova injetados em moldes específicos para produção destes, em comparação dos corpos de prova retirados do produto, sem envelhecimento acelerado;

ii) Estatisticamente, considerando os corpos de prova preparados a partir do produto, não se observa efeito do envelhecimento em água ou sob radiação ultravioleta.

iii) Para os corpos de prova de policarbonato injetados observa-se um efeito antiplasticizante após envelhecimento em água com redução acentuada da deformação na ruptura;

iv) Após o envelhecimento sob radiação ultravioleta, os corpos de prova de policarbonato injetados apresentaram uma acentuada diminuição no alongamento na ruptura sugerindo a ocorrência de reação de transesterificação; e

v) Nas blendas PPO/PS o que se observa é um efeito de redução na alongamento na ruptura para ambos os tipos de corpos de prova e de envelhecimento. Entretanto, cabe assinalar a grande dispersão de resultados nos corpos de prova retirados diretamente do produto confeccionado com a blenda PPO/PS A e aparentemente, considerando-se o desvio médio estatístico, no caso dos corpos de prova injetados de PPO/PS B, o efeito do envelhecimento em água é muito pequeno. Neste caso, uma possível hipótese, e que corroboraria aspectos já anteriormente discutidos, estaria relacionada com um maior percentual de poliestireno nesta blenda, lembrando-se que o poli(óxido de fenileno) PPO é um material mais hidrofílico que o poliestireno. 


\section{Conclusões}

De acordo com os resultados obtidos, algumas considerações gerais devem ser feitas:

i) Verificou-se uma grande variabilidade nos resultados de resistência ao impacto Izod, antes e após envelhecimento em água, de todas as caixas. Isto se deve, principalmente, às diferentes tensões internas presentes em cada região da caixa;

ii) Observou-se também uma grande diferença entre os valores encontrados para resistência ao impacto Izod dos corpos de prova retirados das bases das caixas comparados com os valores encontrados para os respectivos materiais injetados, indicando também a significativa influência dos parâmetros de processamento de injeção, tanto nas caixas como nos corpos de prova injetados; e

iii) De modo geral, os valores de resistência à tração no ponto de máxima deformação plástica não diferem significativamente entre os corpos de prova injetados e os corpos de prova retirados da caixa do mesmo material; contudo, observou-se que esta variação é significativa nos valores de alongamento à ruptura, o que indica que esta propriedade deve ser considerada nas avaliações do comportamento mecânico dos materiais.

\section{Agradecimentos}

Os autores agradecem a colaboração da empresa Plastimax Indústria e Comércio LTDA pelo fornecimento das caixas e dos corpos-de-prova analisados e à Coelba - Companhia de Eletricidade do Estado da Bahia - pelo apoio técnico e financeiro no desenvolvimento deste trabalho.

\section{Referências Bibliográficas}

1. Morton-Jones, D. H. - "Polymer Processing", Chapman \& Hall, London (1994).

2. Inberg, J. P. F. \& Gaymans, R. J. - Polymer, 43, p.4197-4205 (2002).
3. Chen, S. C.; Peng, H. S.; Huang, L. T. \& Chung, M. S. J. Reinf. Plast. Comp., 22, p.479-494 (2003).

4. Ho, C. H. \& Vu-Khanh, T. - Theor. Appl. Fract. Mec., 39, p.107-116 (2003).

5. Huu, C. H. \& Vu-Khanh, T. - Theor. Appl. Fract. Mec., 40, p.75-83 (2003).

6. Ho, C. H. \& Vu-Khanh, T. - Theor. Appl. Fract. Mec., 41, p.103-114 (2004).

7. Brydson, J. A. - "Plastics Materials", Butterworth Heinemann, Oxford, p.584-593 (1999).

8. Ho, J.; Govaert, L. \& Utz, M. - Macromolecules, 36, p.7398-7404 (2003).

9. Suzuki, T.; Yoshimizu, H. \& Tsujita, Y. - Polymer, 44, p.2975-2982 (2003).

10. Sammon, C.; Yarwood, J. \& Everall, N. - Polym. Degrad. Stabil., 67, p.149-148 (2000).

11. Golike, R. C. \& Lasoski Jr., S. W. - J. Am. Chem. Soc., 64, p.895-898 (1960).

12. Silva, D. A.; Betioli, A. M.; Gleize, P. J. P.; Roman, H. R.; Gómez, L. A. \& Ribeiro, J. L. D. - Cem. Concr. Res., 35, p.1741-1746 (2005).

13. Wa, B. Z.; Kao, C. Y. \& Cheng, W. H. - Ind. Eng. Chem. Res., 40, p.509-514 (2001).

14. Ruvolo-Filho, A. \& Curti, P. S. - Ind. Eng. Chem. Res., 45, p.7985-7996 (2006).

15. Mark, J.; Ngai, K.; Graessley, W.; Mandelkern, L.; E. Samulski, E., Koenig, J. \& Wignall, G. - "Physical properties of polymers", Cambridge University Press, Cambridge (2004).

16. Baschek, G.; Hartwig, G. \& Zahradnik, F. - Polymer, 40, p.3433-3441 (1999).

17. Fechine, G. J. M.; Rabello, M. S.; Maior, R. M. \& Catalani, L. H. - Polymer, 45, p.2303-2308 (2004).

18. La Mantia, F. P. - "Recycling of PVC and mixed plastic waste", Chem Tec Publishing, Toronto (1996).

Enviado: 09/10/08

Reenviado: 23/03/09

Aceito: 03/04/09 